\title{
O que fazer com a pequena agricultura? As soluções diante da conservação
}

\section{How can we deal with the small-scale agriculture? Solutions for conservation}

\author{
Cristina TEIXEIRA*
}

\section{RESUMO}

A proteção ambiental desenvolvida nos limites da Área de Proteção Ambiental (APA ) de Guaraqueçaba, litoral norte do Paraná, exigiu dos atores da conservação a reflexão sobre o que fazer com a pequena agricultura, desenvolvida pela maior parte da população que ali se encontrava há muitos anos. Ainda que todas as soluções apresentadas tenham sido definidas em função da conservação, observa-se que elas sofreram mudanças ao longo do processo de proteção ali instaurado. Este artigo analisa a relação entre as soluções e os diferentes atores envolvidos com a conservação nos limites da APA, no período compreendido entre 1981 e 2000.

Palavras-chave: unidade de conservação; conservação e agricultura.

\begin{abstract}
The environmental conservation employed within the limits of the Guaraqueçaba's APA (Conservation Area Zone), northern littoral of the state of Paraná, demanded from conservationists' activists a reflection upon how to deal with the small-scale agriculture, that has been developed for the most part by populations who have been living there for many years. Even that all of the solutions have been presented to them in terms of conservation, they have suffered changes during the process of protection that was estabilished there. This paper analyses the relation between the solutions proposed from 1981 to 2000 and the different participants involved in the process of conservation inside the APA.

Key words: Conservation Area, conservation and agriculture.
\end{abstract}

\footnotetext{
* Doutora em Meio Ambiente e Desenvolvimento pela Universidade Federal do Paraná (UFPR), Professora do Departamento de Teoria e Fundamentos da Educação e do Programa de Pós-Graduação em Educação da UFPR. e-mail: mailto:cristinaft@ufpr.br e cristinaft@ufpr.br

* Departamento de Teoria e Fundamentos da Educação (DTFE)

* Programa de Pós-Graduação e Pesquisa em Educação (DTFE)

* Setor de Educação - UFPR
} 


\section{Apresentação}

No processo de proteção ambiental desenvolvido nos limites da APA de Guaraqueçaba, localizada no litoral norte do Paraná, a conservação se deparou com uma pequena agricultura secularmente instalada, distante de vias de transporte e de possibilidades de comercialização da produção, caracterizada pela pobreza e pela desigualdade de acesso à terra e aos meios de produção. Essa pequena agricultura passou a conviver com restrições de uso dos recursos naturais estabelecidas pelo processo de conservação ali desencadeado, que antecede a criação da APA, em 1985. A regulação de uso dos recursos naturais na área correspondente aos limites da APA ocorreu não só em conseqüência das unidades de conservação ali implantadas. Regulamentações independentes das unidades de conservação foram ali aplicadas, como o Decreto Mata Atlântica de 1990.

Para que se possa ter uma idéia da pequena agricultura local, remete-se aqui ao Macrozoneamento da APA de Guaraqueçaba, de 1990. Esse documento descreve assim a pequena agricultura, caracterizada como familiar, encontrada na APA:

A produção familiar na APA de Guaraqueçaba envolve dois grupos de produtores, que se diferenciam fundamentalmente pela disponibilidade de recursos produtivos, principalmente pelo estoque de terra. Um desses grupos possui reduzido estoque de terra, ao que conjugam-se, em muitos casos, precários vínculos legais com a terra. Esses produtores têm maior dependência de outras atividades para garantir a sobrevivência das famílias, como o assalariamento temporário em fazendas e a coleta do palmito.

O segundo grupo de produtores dispõe de uma área de terra maior (no caso da região, seriam basicamente os produtores situados no estrato de 10 a 50 hectares), o que lhes permite assegurar a manutenção da família através do desenvolvimento da policultura, combinando a produção voltada às necessidades familiares e criação doméstica à produção de culturas destinadas ao mercado, como a da banana.
Entre os dois grupos de produtores não se observa diferenciação em nível técnico, realizando-se a produção praticamente com o recurso da força humana. A vantagem do segundo grupo reside na disponibilidade de uma área maior para o plantio e para o desenvolvimento de certas práticas conservacionistas como o pousio, o que, nas condições de produção que prevalecem nessa área, é fundamental para a preservação da fertilidade do solo (IPARDES, 1990, p. 156).

As ações de conservação nos limites da APA originaram-se no movimento para a conservação do litoral sul de São Paulo e litoral norte do Paraná, em 1970. Nessa região se encontra o principal remanescente de Floresta Atlântica do Brasil e um dos mais importantes complexos estuarinos do planeta, ameaçados por ocupações e exploração dos recursos ali existentes.

A proteção ambiental em Guaraqueçaba iniciou-se antes da criação das unidades de conservação federais naquela região. A partir de 1980 foram criadas algumas áreas de proteção ambiental por parte do estado do Paraná, que, praticamente, não tiveram repercussões sobre a conservação no litoral (TEIXEIRA, 2004). Neste artigo utiliza-se a APA como referência, por compreender uma área extensa onde se desenvolveu um processo de proteção ambiental (TEIXEIRA, 2004) sobre uma ocupação caracterizada, majoritariamente, pela pequena agricultura. Com uma extensão de $3.143 \mathrm{~km}$ e 8.288 habitantes, a APA de Guaraqueçaba possui a maior parte de sua população, $68,85 \%$, vivendo na zona rural, na qual a pequena agricultura corresponde à maior parte das atividades produtivas locais, principalmente a produção de banana e mandioca (RODRIGUES, 2002).

Sobre as dificuldades de produção e comercialização dos pequenos produtores, historicamente estabelecidas ${ }^{1}$, recaem restrições ao uso dos recursos naturais que dificultam, ainda mais, as suas condições de reprodução socioeconômica. Suas práticas produtivas, muitas ainda tradicionais, voltadas à comercialização em pequena escala ou à subsistência, foram consideradas inadequadas aos objetivos da conservação dos recursos naturais. A queimada, a caça, o desenvolvimento de culturas em áreas inapropriadas, o extrativismo, por exemplo, foram regulamentados por órgãos federais e estaduais responsáveis pela conservação

1 Essa região já passou por um momento de prosperidade, do final do século XIX ao início do século XX, decorrente do desenvolvimento da produção e da comercialização de produtos agrícolas, principalmente a banana. O período de prosperidade foi seguido pela crise do modelo econômico local,que levou o município à decadência econômica e cultural a partir dos anos 1930, caracterizada, entre outros aspectos, pelo empobrecimento dos agricultores locais, particularmente da pequena agricultura familiar (MIGUEL, 1997). 
ambiental, atingindo diretamente os interesses da pequena agricultura em relação ao uso dos recursos naturais. $\mathrm{Ou}$ seja, a conservação tornou-se mais um obstáculo para as dificuldades de sua auto-reprodução (MIGUEL, 1997; MIGUEL; ZANONI, 1998), instaurando um conflito de uso dos recursos naturais que se estende até os dias de hoje.

O processo de proteção ambiental em questão não direcionou suas propostas e ações de conservação para a exclusão da população local dos limites das áreas protegidas. A APA é uma categoria de unidade de conservação que mantém a ocupação humana nela existente e estabelece a gestão das práticas de uso dos recursos naturais. Em Guaraqueçaba, isso implicou na necessidade dos atores da conservação em responderem à seguinte questão: o que fazer com a pequena agricultura na APA, em função da conservação?

Uma vez a conservação estabelecida como objetivo para o litoral norte do Paraná, o que fazer em relação às práticas de uso dos recursos naturais realizadas por essa agricultura? O que fazer para reduzir os efeitos da regulamentação de uso desses recursos sobre as dificuldades de reprodução da mesma? As soluções apresentadas se diferenciaram ao longo do tempo em que a proteção ambiental foi ali instaurada. Os primeiros atores da conservação partiram de um paralelismo entre a conservação e a necessidade de desenvolvimento socioeconômico e justiça social, no qual as questões sociais pertinentes à pequena agricultura eram centrais. Os novos atores que os substituíram chegaram à solução para a pequena agricultura absolutamente determinada pela pesquisa e pela técnica adequada à conservação.

O objetivo era proporcionar práticas produtivas adequadas, nas quais as questões sociais se diluíram no imperativo da conservação.
Uma multiplicidade de fatores interferiu na mudança das soluções apresentadas para a pequena agricultura, e estes foram analisados em um estudo mais amplo sobre a proteção ambiental na APA de Guaraqueçaba. ${ }^{2}$ Contudo, neste artigo destaca-se apenas a relação entre as soluções e seus autores, mais especificamente, os principais atores da conservação. Órgãos governamentais ambientais estaduais e federais - e organizações não-governamentais (ONGs) idealizaram e executaram a conservação através de seus técnicos e fiscais. A partir de seus interesses, de suas instituições, conjunturalmente condicionados, elaboraram propostas de soluções para a pequena agricultura local em função da conservação ${ }^{3}$, nem sempre executadas.

Ao realizarem proposições para a pequena agricultura local, os atores da conservação estão inseridos em posições sociais, a partir das quais articulam as condições subjetivas e objetivas de realização de suas ações, elaborando respostas solicitadas por uma determinada situação. ${ }^{4}$ No caso, a situação era estruturada pela conservação ambiental em face à reprodução da pequena agricultura local.

\section{A conservação diante dos problemas socioambientais: a pequena agricultura entre a questão social e a conservação}

Desde a criação do Código Florestal, em 1965, que já regulamentava a colheita e a transformação do palmito, a região onde se encontra a APA de Guaraqueçaba foi alvo de restrições à utilização dos recursos naturais. Contudo, foi a partir da década de 1980 que essas restrições se vincularam à conservação propriamente dita.

2 Referência à TEIXEIRA, C. A proteção ambiental em Guaraqueçaba: uma construção social (2004).

3 Nesse sentido, atores como o Batalhão da Polícia Florestal, que atuava na fiscalização, e diversas ONGs que atuaram em Guaraqueçaba nos anos 90, não serão considerados. Embora atuassem junto à pequena agricultura, estas últimas em ações de geração de renda, organização comunitária e outras, esses atores não eram os responsáveis pela elaboração de propostas "oficiais" de conservação e desenvolvimento para toda a região. Para mais detalhes sobre a atuação desses atores, ver TEIXEIRA (2004).

4 Esse esquema explicativo foi retirado da teoria da ação social de Pierre Bourdieu (1930-2002), segundo a qual "a Sociologia deve incluir uma Sociologia da construção das visões de mundo, que também contribuem para a construção desse mundo. Porém, dado que nós construímos o espaço social, sabemos que esses pontos de vista são, como a própria palavra diz, visões tomadas a partir de um ponto, isto é, a partir de uma determinada posição no espaço social. E sabemos também que haverá pontos de vista diferentes, e mesmo antagônicos, já que os pontos de vista dependem do ponto a partir do qual são tomados, já que a visão que cada agente tem do espaço depende de sua posição nesse espaço.” In: BOURDIEU, P. Espaço social e poder simbólico. In __. Coisas ditas. São Paulo: Brasiliense, 1990. Sobre o mesmo assunto, ver, além desse livro, do mesmo autor, Razões práticas: sobre a teoria da ação. Campinas: Papirus, 1996, e Questões de sociologia. Rio de Janeiro: Marco Zero, 1983. 
A primeira década da proteção ambiental em Guaraqueçaba é concomitante ao período de desenvolvimento do movimento ambiental e a instituição da questão ambiental no Brasil, fatores responsável por trazerem, definitivamente, o debate sobre o meio ambiente para o poder público (ACSELRAD, 2001; LEIS; VIOLA, 1996).

A discussão internacional sobre a relação entre crescimento econômico e meio ambiente, que no início dos anos 1980 ainda não fazia referência ao desenvolvimento sustentável (NOBRE, 2002), e a discussão sobre a ocupação humana em unidades de conservação, que colocava cada vez mais a necessidade de gestão de espaços para a conservação (BRITO, 2000), foram lentamente incorporadas por órgãos governamentais e ONGs no Brasil. Novas categorias de unidades de conservação foram criadas, nas quais se aplicaria a idéia de uso racional dos recursos naturais, como no caso da APA, além da idéia da necessidade de proteção de práticas tradicionais afins à conservação desses recursos.

Paralelamente, a redemocratização do Brasil, após a abertura política do governo militar, influenciou a "politização" do movimento ambiental e a democratização da questão ambiental, enfatizando a crítica ao modelo de desenvolvimento brasileiro. Os anseios de justiça social, até então exteriores ao Estado, puderam se manifestar na administração pública, inclusive nos órgãos relacionados ao meio ambiente (TEIXEIRA, 2004).

A partir das eleições de 1982, o estado do Paraná acompanhou essas transformações ocorridas internacional e nacionalmente, porém dando uma característica própria à sua política ambiental, que se refletiu na conservação em Guaraqueçaba. Políticas públicas procuraram solucionar, de forma integrada, os problemas decorrentes do impacto ambiental e do impacto social da modernização agrícola, tais como o desmatamento, a erosão e a expropriação do pequeno produtor de suas terras. Atenção especial foi dada à agricultura familiar, principal vítima dessa modernização (FLEISCHFRESSER, 1988; MIGUEL, 1997; PARANÁ, 1985; ZANONI; RAYNAUT, 1994). Em 1984 foi instituído o Programa de Estado para o Meio Ambiente (PEMA), considerado inovador, pois negava a idéia de que o meio ambiente é objeto apenas da conservação e propunha a inclusão da preocupação ambiental como parte de outras políticas e ações de desenvolvimento do Estado (MIGUEL, 1997). Em relação ao litoral paranaense, principalmente mediante as ameaças da ocupação para veraneio, foi criado o Conselho do Litoral, em 1984, que executou a Lei de Uso do Solo do Litoral, de 1980.

Mas, apesar do quadro acima, as políticas públicas estaduais não consideraram o litoral norte como região prioritária para a aplicação dos programas de desenvolvimento (FLEISCHFRESSER, 1988). O município de Guaraqueçaba recebeu insuficientes e inadequadas iniciativas de programas de desenvolvimento para a pequena agricultura, cuja principal produção era a banana, a mandioca e o feijão (MIGUEL, 1997; ROCHA, 2004).

Desde os anos 60, os programas de incentivos fiscais, particularmente o FISET - Fundos de Investimento Setoriais (1974), atraíram para Guaraqueçaba empresas madeireiras e grupos industriais e comerciais, que instalaram grandes propriedades destinadas à exploração dos recursos naturais ou à especulação, boa parte deles estendendo as atividades que já desenvolviam no litoral sul de São Paulo. Estes foram denominados por Miguel (1997) de neolatifundiários e chegaram a se apropriar de $80 \%$ do território da região, utilizando os recursos captados nos programas federais para outros fins. Eles desenvolveram a bubalinocultura, o extrativismo, principalmente a exploração de madeira na forma de exploração seletiva e ilegal (PARANÁ. SEPL, 1987, p. 4).

Essa ocupação, através de regularização duvidosa de posses ou "grilos", acarretou a concentração fundiária e a minifundização das propriedades locais. Isso ocorreu através de conflitos violentos que resultaram, em geral, no deslocamento espacial dos pequenos agricultores para terras menos férteis, com menor acesso aos recursos florestais. Muitos só conseguiram se manter através da agricultura de subsistência ou do trabalho em atividades remuneradas fora de sua produção (MIGUEL, 1997; KARAM; TOLEDO, 1996).

Nesse período, iniciou-se a construção de estradas para dar acesso ao município de Guaraqueçaba, impulsionada pelos neolatifundiários para escoamento da produção e acesso às suas propriedades. Insistentemente, estes procuraram construir, mesmo à revelia das proibições, a BR-101, que atravessaria o litoral e ligaria Guaraqueçaba a São Paulo (DOMINGUES; TEIXEIRA, 2002).

Juntamente com o esgotamento dos recursos pesqueiros, essa conjuntura acelerou a delimitação de unidades de conservação, então reivindicadas por ambientalistas 
paulistas e técnicos da Secretaria Especial do Meio Ambiente (SEMA) do governo federal que idealizaram a proteção do Lagamar, um complexo estuarino-lagunar que se estenderia de Iguape, no litoral paulista, até Paranaguá, no litoral paranaense (TEIXEIRA, 2004). A Estação Ecológica, categoria principal de unidade de conservação da SEMA, foi criada em 1982. Para assegurar a Estação Ecológica, foi criada a APA em 1985. O Parque Nacional do Superagüi, fora do continente, foi criado em 1989.

Em 1980, os primeiros atores da conservação chegam à Guaraqueçaba. Seguindo a política do estado do Paraná de regulamentação fundiária, o Instituto de Terras e Cartografia (ITC), órgão subordinado à Secretaria de Agricultura do Paraná (SEAB), instala escritório em Guaraqueçaba. Órgão originariamente voltado à regulamentação da ocupação de terras no estado, o ITC acrescentou às suas atribuições de órgão de terras o controle da exploração dos recursos naturais, principalmente dos recursos florestais. Em 1985 esse órgão passa a ser chamado de Instituto de Terras, Cartografia e Floresta (ITCF). O principal objetivo dessa instalação não foi a conservação, mas a regularização fundiária para proporcionar aos agricultores locais o acesso aos programas e financiamentos agrícolas, que exigiam a titulação de terras. Ao mesmo tempo, essa regularização objetivava impedir o avanço das grandes empresas sobre Guaraqueçaba, evitando seus impactos ambientais e sociais (TEIXEIRA, 2004).

Muitos ambientalistas, ou simpatizantes do movimento ambiental, eram ou se tornaram técnicos de órgãos governamentais. Ou seja, o movimento ambiental estava presente nos órgãos estaduais. Segundo um técnico do ITC, "os ambientalistas éramos nós". Assim, no que se refere às determinações voltadas ao meio ambiente, as condições específicas do poder público e do movimento ambiental do Paraná (URBAN, 2001) incluíram na questão ambiental uma dimensão social que a política ambiental nacional tinha dificuldade em fazer.

Afinados com a política ambiental agrícola do estado, os técnicos que instalaram os escritórios no litoral eram basicamente engenheiros agrônomos e técnicos agrícolas, pertencentes à associação dos agrônomos do estado do Paraná, esta última, tradicionalmente, uma associação crítica dos efeitos perversos do modelo agrícola vigente no estado. Eles gravitavam em torno do tema da "justiça social", por exemplo, através da defesa da reforma agrária (TEIXEIRA, 2004).
As ações de conservação realizadas pelo ITC/ITCF eram ações de fiscalização e de licenciamento. Os depoimentos de fiscais e técnicos que trabalharam em Guaraqueçaba confirmam que eram ações "policialescas", cujo objetivo principal eram as interdições da exploração dos recursos naturais pelos palmiteiros e neolatifundiários, sobretudo da madeira. O ITC/ITCF atuou, também, juntamente com a SEMA e com o Conselho do Litoral, nas ações de embargo das tentativas de construção da BR-101 e instalação de complexos hoteleiros e empresas de exploração de recursos (naturais e humanos ${ }^{6}$ ), para impedir o avanço dos neolatifundiários na região, a principal ameaça à conservação.

Essas ações desestimularam os grandes empreendimentos, reduzindo a grilagem e a exploração dos recursos naturais, já em meados dos anos 1980. Contudo, alguns neolatifundiários mantiveram a propriedade de suas terras com vistas à valorização fundiária. Aqueles que permaneceram desenvolveram principalmente a bubalinocultura, considerada de importante impacto sobre o ambiente, até o final dos anos 90 (MIGUEL, 1997; RODRIGUES, 2002). Com isso praticamente cessaram os conflitos de terra e as do estado para a regularização fundiária, embora esta não tenha sido efetivada (DOMINGUES; TEIXEIRA, 2002). A exploração de recursos naturais que se manteve, apesar do insistente controle, foi a extração ilegal do palmito (MIGUEL, 1997), considerada a mais difícil de ser fiscalizada e interditada em Guaraqueçaba (TEIXEIRA, 2004).

Para os técnicos do ITC/ITCF, a pequena agricultura não representava uma ameaça ao meio natural. Ela teria mesmo contribuído para a conservação dos recursos naturais devido à utilização de práticas tradicionais de produção. As poucas práticas condenadas, como a queimada, ocorriam em pequena escala e não eram consideradas responsáveis pela degradação ambiental (TEIXEIRA, 2004). Segundo um dos fiscais do ITC/ITCF, “....algumas técnicas tradicionais poderiam continuar a existir: agricultura com a técnica do pousio, uso coletivo da terra, que se procurava manter regularizando a propriedade (...) Eles promoveram a conservação e não a degradação.” As práticas não apropriadas à conservação realizadas pela pequena agricultura, tais como o pousio, a redução do tempo entre as queimadas e o desenvolvimento de culturas em locais "frágeis" ambientalmente, resultavam de problemas exteriores à pequena agricultura, entre eles, a

6 Nas entrevistas com os técnicos do ITC/ITCF e na imprensa da época, havia relatos de utilização de trabalho escravo em uma empresa instalada na região (MIGUEL, 1997;TEIXEIRA, 2004). 
questão fundiária. Assim, ao considerarem a necessidade de conservação ambiental, acreditavam que as ações de regularização fundiária e impedimento de ocupação irregular por parte dos neolatifundiários eram ações prioritárias.

Segundo Miguel (1997), o controle de uso dos recursos naturais através da legislação vigente era rigoroso, impedindo práticas que eram significativas para a sobrevivência e a reprodução da pequena agricultura local. Além disso, a burocratização do licenciamento atrapalhava ou impedia o desenvolvimento do calendário agrícola do sistema de cultivo de queimada, o que poderia inviabilizar o plantio (MIGUEL; ZANONI, 1998).

Para os técnicos do ITC/ITCF, o Código Florestal não era rigoroso em relação à regulamentação de uso dos recursos naturais. As modificações na Lei do Uso do Solo do Litoral, principalmente após o decreto que regulamentou a utilização de áreas rurais acima da cota altimétrica de 20 metros (Decreto 8.743/86), tornaram as sanções e a fiscalização mais rigorosas (TEIXEIRA, 2004). Conforme afirmações de técnicos do órgão estadual, que corroboram com as constatações de Miguel (1997), além de prejudicar a prática do pousio, essa regulamentação teria causado danos ambientais, uma vez que levava o agricultor a explorar o mesmo solo até seu esgotamento. Mas eles consideravam que a função do órgão era aplicar essa regulamentação, o que não impedia que, em determinadas situações, fechassem os olhos para algumas irregularidades realizadas por pequenos agricultores (TEIXEIRA, 2004).

Para esses atores, a regularização fundiária e o controle deveriam ser acompanhados por ações de desenvolvimento e por ações assistenciais. Incluíam ações de saúde (vacinação) e de polícia florestal. Segundo o depoimento de um fiscal do ITC/ITCF, “...trabalho de polícia florestal, que quase não ia a Guaraqueçaba (...) eles chamavam a gente, nós éramos a polícia deles". Além disso, era imprescindível a organização política da população local, para enfrentarem os seus problemas, como a formação do Sindicato dos Trabalhadores Rurais, que foi organizado junto com o órgão estadual.

Essas ações acima citadas não eram atribuições do ITC/ITCF. Mesmo assim, os técnicos se empenhavam em atrair esse desenvolvimento para a região (assistência técnica, implantação de programas, etc.), sem, necessariamente, haver uma adequação dos programas à conservação. Realizaram, ainda, campanha de vacinação, organização de associação de produtores e outras fora de suas atribuições. Tais ações refletiam a articulação existente entre a conservação e a defesa da pequena agricultura que não protegida por ser somente uma agricultura tradicional e, portanto, conservadora. Antes de serem considerados uma população tradicional, os pequenos agricultores de Guaraqueçaba eram vistos pelos técnicos do ITC/ITCF como agricultores que viviam em condições precárias. Segundo um de seus técnicos: “....a gente não pensava em termos de população tradicional. Nós agíamos sobre os que lá viviam e que estavam ameaçados ou que precisavam de regularização de suas terras (...) Não era só polícia e fiscalização. Pensávamos nos pequenos que viviam lá.” De fato, essa era uma "causa" abraçada pelo órgão governamental que se expressava paralelamente à conservação.

$\mathrm{O}$ desenvolvimento da pequena agricultura se justificava não só pelo sentimento da necessidade de melhoria da qualidade de vida da população local, mas também para que ela abandonasse práticas irregulares e contrárias aos interesses da conservação, como a coleta ilegal do palmito entregue aos palmiteiros. Os técnicos do ITC/ITCF, a partir de suas posições, fizeram valer a atenção especial às questões sociais. Segundo depoimento de um deles, na definição das ações do órgão em Guaraqueçaba, o mais importante era a conservação. Mas a convivência com a pequena agricultura local relativizou a conservação: "Ocorre que a questão ambiental pegava mais. A injustiça social era mais para nós, técnicos agrícolas, todos de classe média baixa." Ao lado da formação profissional e do envolvimento com movimentos políticos e sociais, a origem social influenciara as ações dos atores da conservação.

Outro ator importante no processo de proteção ambiental, nos anos 1980, era a SEMA. Suas principais ações estavam voltadas para a implantação das unidades de conservação que eram criadas na região (formação de grupo interinstitucional, zoneamento, construção da sede, etc.). A implantação era realizada com escassos recursos financeiros e humanos, característica da SEMA. Assim, pouco foi realizado nesse período (TEIXEIRA, 2004).

Somente um técnico (chefe da Estação e da APA) atuava esporadicamente em Guaraqueçaba, concentrandose na Estação Ecológica, ocupada por uma população de pescadores. Esse técnico havia incorporado a discussão sobre população tradicional, especialmente pescadores,

7 Discussão desenvolvida pelo Núcleo de Pesquisas sobre População Humana em Áreas Úmidas Brasileiras (NUPAUB), que havia realizado um estudo específico sobre as comunidades pesqueiras de Guaraqueçaba. 
que considerava que o controle de uso dos recursos naturais interferia nas práticas tradicionais, ameaçando a reprodução das mesmas. ${ }^{7}$ Ele fazia parte de um grupo de ambientalistas que, desde o início dos anos 1980, participara das discussões e campanhas para a proteção do Lagamar. Esse grupo elaborou, em 1987, um dossiê ${ }^{8}$ dessa região, no qual o diagnóstico da pequena agricultura local seguia as posições dos técnicos do ITC/ITCF. Ainda, a relação de proximidade do mesmo técnico com a direção da SEMA proporcionou um intercâmbio de idéias e uma relação de cooperação entre os órgãos estaduais, os ambientalistas e a SEMA, promovendo uma construção homogênea de soluções para a pequena agricultura entre eles. Por esse motivo, mesmo após a criação da APA, a SEMA mantém a fiscalização e o licenciamento sob responsabilidade do ITC/ITCF (TEIXEIRA, 2004).

Diferentemente do ITC/ITCF, cujas atribuições institucionais e conjuntura estadual levavam diretamente à questão fundiária e à agricultura, a SEMA restringiu seu interesse à conservação, embora participasse de algumas reuniões com agricultores e tivesse se empenhado, juntamente com o órgão estadual, em impedir o avanço dos neolatifundiários. O olhar da SEMA sobre a pequena agricultura local foi significativamente influenciado pelo ITC/ITCF, um olhar que, segundo depoimento do chefe da Estação e da APA, ainda não sabia exatamente o que fazer com a pequena agricultura em função da conservação: "Na época não se falava muito em desenvolvimento, conselho, participação (...) não se tinha a idéia tão clara do que fazer com a comunidade." Melhor dizendo, o olhar do seu representante foi influenciado pelo órgão estadual, pois, segundo o mesmo, a idéia de conservação na SEMA, no que se refere ao tratamento dispensado à população em unidade de conservação, "era dividida".

O Macrozoneamento da APA de Guaraqueçaba, documento da SEMA, elaborado em 1989 por um órgão estadual de desenvolvimento (IPARDES, 1990), sintetiza o direcionamento dado pelos principais atores da conservação em Guaraqueçaba em relação ao diagnóstico e à solução para a pequena agricultura diante da conservação desejada para a região. Assim como o ITC/ITCF, no documento não havia previsão de outras atividades para o pequeno agricultor além da agricultura. Mas, para isso, era necessário garantir os "recursos materiais e técnicos", isto é, o uso da terra e programas de desenvolvimento agrícola e assistência técnica. Conforme constatava o Macrozoneamento da APA:

\begin{abstract}
O que se procurou evidenciar (...) é que a capacidade de adequação por parte desses grupos sociais ao novo padrão de uso do solo e água e de seus recursos, decorrente do zoneamento, está relacionada à disponibilidade de recursos materiais e técnicos para o desenvolvimento de suas atividades produtivas que, no caso dos pescadores artesanais e dos pequenos produtores rurais, é precária (IPARDES, 1990, p. 154).
\end{abstract}

\section{A pequena agricultura em função da conservação}

A partir dos anos 1990, a proteção ambiental em Guaraqueçaba caracterizou-se pela implantação efetiva das unidades de conservação criadas pela SEMA na década anterior. Os principais atores da conservação dessa década foram o IBAMA, que substituiu a SEMA em 1989, e as ONGs ambientalistas. O ITCF reduziu gradativamente sua participação no processo de proteção ambiental na APA de Guaraqueçaba, cessando suas atuações em 1999.

Nesse mesmo período, a realização da Rio-92 legitimou a noção de desenvolvimento sustentável, que se refletiu na idéia de uso sustentável dos recursos naturais, presente nas diretrizes internacionais e nacionais de unidades de conservação (BRITO, 2000). As ONGs, cada vez mais participativas nos rumos da conservação no Brasil, se organizaram e se profissionalizaram, imprimindo a racionalidade técnica-científica em suas ações. Foi o momento da "cientifização" do movimento ambiental e da sua despolitização (DEAN, 2000; LEIS; VIOLA, 1996). Nesse momento, também se desenvolveu o conhecimento científico sobre a conservação de ecossistemas, incluindo o conhecimento da relação entre conservação e a ocupação humana (DIEGUES, 2000).

8 FUNDAÇÃO SOS PRÓ-MATA ATLÂNTICA. Dossiê complexo estuarino lagunar de Iguape, Cananéia e Paranaguá. São Paulo, 1986.

9 Respectivamente: Programa Nacional do Meio Ambiente (1991), Projeto de Conservação e utilização Sustentável da Diversidade Biológica Brasileira (1996) e Programa Piloto para Proteção das Florestas Tropicais do Brasil (1992). 
Os financiamentos internacionais para programas de proteção ambiental no Brasil $^{9}$ permitiram o desenvolvimento de ações voltadas à implantação de unidades de conservação. A necessidade de recursos técnicos e financeiros por parte dos órgãos ambientais, aliada à profissionalização e à capacidade de captação de recursos das ONGs, propiciou o desenvolvimento de parcerias entre essas instituições para a realização de ações de conservação (TEIXEIRA, 2004).

No estado do Paraná, o governo de 1991 retomou a discussão sobre o meio ambiente à luz da Rio-92. Promoveu a reorganização administrativa, criando órgãos públicos autônomos para tratar as questões relativas ao meio ambiente. Essa reorganização gerou melhor aparelhamento do estado para lidar com a questão ambiental e com a gestão dos recursos financeiros destinados à conservação. Em 1992, foram criados a Secretaria de Estado do Meio Ambiente e Recursos Hídricos (SEMA) e o Instituto Ambiental do Paraná (IAP). Este, uma fusão do ITCF com a Superintendência dos Recursos Hídricos, ficou subordinado à recém-criada SEMA do Paraná. Nessa reorganização, ressalta-se que a atenção especial dada à agricultura familiar deixa de existir nos órgãos ambientais, estes não mais vinculados à SEAB.

A reorganização administrativa não foi acompanhada de investimento em recursos humanos, em infra-estrutura e em efetiva modernização administrativa. O processo de desestatização nacional se reproduziu no Paraná, interferindo no alcance e no desempenho dos órgãos ambientais paranaenses (TEIXEIRA, 2004).

Na segunda metade dos anos 90, o governo estadual investiu na captação de recursos financeiros para o desenvolvimento das ações ambientais, incentivando ações consorciadas em parceria com a iniciativa privada e a sociedade civil organizada. Assim como na esfera federal, os rumos da política ambiental passaram a ser orientados por programas (PARANÁ. SEMA, 1994) para os quais houvesse financiamento, ${ }^{10}$ e não por uma política pública propriamente dita (TEIXEIRA, 2004).

Guaraqueçaba permaneceu como um município sem importância econômica e política para o estado do Paraná e sua pequena agricultura não avançou em relação às suas condições estruturais de reprodução. As vias de transporte permaneceram insuficientes e precárias e os indicadores socioeconômicos do município evidenciavam a situação de pobreza da pequena agricultura e a falta de infra-estrutura e serviços básicos, além da manutenção da concentração fundiária. Os programas voltados à pequena agricultura praticamente não alcançaram Guaraqueçaba. Isso só ocorreu em ações independentes, de curta duração, com poucos recursos e sob a falta de cooperação interinstitucional (MIGUEL, 1997; SPVS/TNC, 1992; ROCHA, 2004; RODRIGUES, 2002).

Ainda que o município tenha recebido o ICMS ecológico ${ }^{11}$ a partir do início dos anos 1990 , isso não se reverteu em melhorias econômicas e sociais significativas para a pequena agricultura. Atribui-se essa situação à incapacidade gerencial dos administradores municipais e às estratégias "desfocadas", segundo expressão utilizada por Rocha (2004), das reais necessidades da sociedade local.

Nos anos 1990, permanece a dificuldade de reprodução do sistema produtivo e do sistema familiar que caracterizava a pequena agricultura local: “...uma economia agrícola frágil, que mesmo nos curtos períodos de relativa opulência não permitiu à maioria das famílias se diferenciarem 'para cima' e entrar no circuito da acumulação de riqueza" (RODRIGUES, 2002, p. 65). Identifica-se um processo de empobrecimento da pequena agricultura, em decorrência da falta de competitividade da produção local e das restrições de uso dos recursos naturais (MIGUEL, ZANONI, 1998). Ainda, a situação fundiária local, não solucionada na década anterior, favorecia o uso "intensivo e depredatório" dos recursos ambientais, interferindo no gerenciamento das unidades de conservação ali instaladas (SPVS/TNC, 1992, p. 212). Embora os impactos causados pela pequena agricultura fossem considerados pouco importantes, os novos atores da conservação consideravam que ela merecia especial atenção, pois os $31 \%$ do município por ela ocupados correspondiam às planícies costeiras e vales dos rios (MIGUEL, 1990, apud SPVS/TNC, 1992).

Em relação à década anterior, algumas práticas produtivas combatidas pela conservação sofreram redução significativa, por exemplo a extração da madeira. Porém,

10 Este é o caso do programa Pró-Atlântica, iniciado em 1997, com duração de cinco anos, que envolveu órgãos estaduais e ONGs e foi patrocinado pelo banco KFW. 11 A Constituição do Estado do Paraná de 1988 estabeleceu que 5\% dos 25\% da arrecadação do ICMS destinados ao Fundo de Participação dos Municípios deveria ser repartido entre os municípios com áreas de proteção ambiental, procurando compensá-los das restrições ambientais que, em princípio, prejudicariam o seu desenvolvimento, instituindo, assim, o ICMS Ecológico. 
outras se mantiveram, como a bubalinocultura e a coleta de palmito, agravada com a instalação de fábricas clandestinas. Outras ainda se originaram, como o turismo (MIGUEL, 1997; RODRIGUES, 2002; SPVS, 1994).

Além das unidades de conservação e da legislação vigente, outro instrumento de proteção ambiental se estabeleceu em Guaraqueçaba: a Reserva da Biosfera Vale do Ribeira - Serra da Graciosa criada em 1991. Isso facilitou a aquisição de convênios e recursos, especialmente para as ONGs ambientalistas que ali desenvolveram suas ações. ${ }^{12}$ Um pool de financiamentos ${ }^{13}$ tornou possível a realização de ações vinculadas à conservação junto à sociedade local (SPVS, 1995).

A APA recebeu recursos do Programa Nacional do Meio Ambiente (PNMA) para a sua implantação. Uma reelaboração do zoneamento e o plano de gestão, exigidos para a implantação, foram então encaminhados.

Os novos atores da conservação em Guaraqueçaba possuíam um perfil diferente dos principais atores da década anterior e representavam um novo contexto em relação à conservação, acima identificado. A administração da APA de Guaraqueçaba, a partir de 1991, passou a ser responsabilidade do novo chefe da Estação Ecológica. Em 1993, outro técnico assume a chefia da APA, tendo realizado um curso de especialização em administração de unidade de conservação (TEIXEIRA, 2004), ou seja, possuía capacitação específica para a conservação.

No mesmo período, articuladas ou não ao IBAMA, ONGs ambientalistas ou afins foram atraídas para a região, realizando pesquisas e propondo soluções para o uso sustentável dos recursos naturais. Elas realizaram ações em diferentes dimensões, entre elas educação ambiental, organização de associação para gestão de ações de desenvolvimento e projetos de geração de renda (TEIXEIRA, 2004).

Entre as ONGS, destacou-se a Sociedade de Pesquisa em Vida Selvagem e Educação Ambiental (SPVS), que estabeleceu uma relação de cooperação técnica com o IBAMA, suprindo a necessidade desse órgão de recursos humanos para a elaboração dos instrumentos necessários à implantação da APA. Essa ONG foi criada em 1984 por um grupo de estagiários de um museu de história natural de Curitiba, a maior parte deles com formação na área de biologia. Seu objetivo era a conservação da natureza a partir do desenvolvimento de pesquisas e ações técnico-científicas sobre o ambiente.

Após a conclusão do Macrozoneamento da APA de Guaraqueçaba em 1989, o IBAMA havia estreitado relações com a SPVS para a elaboração do plano de gestão. Em 1994, assinou um termo de cooperação técnica com a SPVS/TNC ${ }^{14}$ e firmou um convênio de co-gestão da APA. Os recursos não seriam exclusivos do PNMA. Caberia à ONG captar recursos para desenvolvimento de pesquisa e de planos de manejo, estes sempre em maior valor do que os recursos do poder público. Observa-se que o convênio deixava a cargo da SPVS uma responsabilidade muito grande sobre a gestão, caracterizando o que o IBAMA definiria mais tarde como "parceria no processo decisório", na qual os parceiros participam das decisões no planejamento básico das unidades de conservação (Planos de Manejo e Plano de Gestão) (TEIXEIRA, 2004).

Em 1992, a SPVS elaborou o Plano Integrado que envolveu 14 técnicos de áreas de conhecimento distintas. Nesse plano, considerou-se que

...a grande maioria das atividades antrópicas desenvolvidas na região são, se não incompatíveis, conflitantes com os objetivos de conservação de um dos últimos remanescentes da Floresta Atlântica e do complexo estuarino (SPVS/TNC, 1992, p. 19),

inclusive as atividades da pequena agricultura. Ressalta-se que o diagnóstico que subsidia o Plano Integrado afirmava que Guaraqueçaba possuía uma "vocação" para a conservação e a necessidade de sua gestão através do "modelo de desenvolvimento conservacionista" (TEIXEIRA, 2004), para o qual a educação ambiental seria utilizada como instrumento de adaptação às novas exigências colocadas pela conservação.

12 O Plano de Gestão Ambiental da APA de 1995 listou 36 instituições atuando em Guaraqueçaba, além dos órgãos estaduais e de duas universidades (UFPR e PUC-PR). Contudo, a maior parte destas entidades não realizava ações significativas em Guaraqueçaba (PARANÁ, 1995).

13 Os projetos realizados pelo convênio receberam recursos públicos do IBAMA - PNMA e do Ministério do Meio Ambiente e Amazônia Legal - Fundo Nacional do Meio Ambiente (FNMA). Contaram ainda com recursos da Fundação O Boticário, do Unibanco Ecologia, da MacArthur Foundation e da U.S.D.A Forest Service.

14 A TNC - The Nature Conservancy é uma ONG norte-americana com financiamentos e ações voltados à conservação em vários países do mundo. Geralmente age através de intermediações de ONGs dos países envolvidos. 
As principais atividades agropecuárias que degradavam os ecossistemas eram a criação extensiva de búfalos, a extração predatória do palmito e de outras espécies arbóreas, o uso de agrotóxico e carência de práticas de conservação de solos. Em relação às práticas agrícolas tradicionais,

“...o desmatamento e a intensificação do uso do solo, como elementos predominantes dos modelos tradicionais de desenvolvimento, são absolutamente rejeitados como formas de atividade econômica" (TEIXEIRA, 2004, p. 12).

A responsabilidade da degradação passa a ser considerada a partir das práticas de uso dos recursos naturais, e não mais a partir de grupos sociais distintos. A solução, então, é a racionalização do uso dos recursos naturais, "visando colocar de forma correta os recursos naturais à disposição de sua população" (TEIXEIRA, 2004), seja ela o produtor de arroz, o bubalinocultor ou o pequeno agricultor. Para a pequena agricultura, então, como para os demais produtores, propõe-se a adequação de suas práticas à conservação. Na impossibilidade de manutenção da atividade produtiva, alternativas como o trabalho no turismo e na produção artesanal poderiam substituir as práticas inadequadas à conservação (extração de palmito, cultivo em áreas proibidas...) (ROCHA, 2004; TEIXEIRA, 2004).

Em linhas gerais, as propostas para a pequena agricultura objetivavam criar condições para o uso racional dos recursos naturais. Para isso, a partir de pesquisas sobre os sistemas de produção, deveriam ser implantadas culturas comerciais, incentivando-se o uso do controle biológico. As indústrias caseiras, já incentivadas pela EMATER/PR, estimulariam a produção de matéria-prima, principalmente a produção frutífera. Pesquisas deveriam ser realizadas visando a sustentabilidade da bananicultura e de outras culturas. O desenvolvimento da monocultura florestal com espécies exóticas não era aceito (SPVS/TNC, 1992, p. 23).

Já não há mais atenção à pobreza e/ou a questão social em si. A afinidade com a agricultura dos agrônomos e técnicos agrícolas do ITC/ITCF, engajados em movimentos por justiça social, deu lugar à afinidade com o meio natural dos técnicos e pesquisadores das ciências naturais, ou ainda das ciências sociais, engajados com o conservacionismo. Considera-se que houve um processo de naturalização da sociedade, onde prevalecem as soluções técnicas sobre as sociais (TEIXEIRA, 2004).
Para a pequena agricultura mantinha-se a necessidade de controle de uso dos recursos naturais. Porém, para possibilitar o uso racional, uma revisão da legislação vigente seria necessária (TEIXEIRA, 2004), especialmente do Decreto Mata Atlântica (Decreto Federal n. 99.547/90), que dispunha sobre a proteção da vegetação nativa da Mata Atlântica de forma bastante restritiva, impedindo o desenvolvimento de lavouras e de práticas materiais cotidianas, como a construção de casas e a caça para a complementação alimentar (MIGUEL, ZANONI, 1998; SPVS/TNC, 1992). Em resposta à reação por parte da sociedade, inclusive dos órgãos ambientais do Paraná e do IBAMA (TEIXEIRA, 2004), um novo decreto de 1993 tornou passível de corte raso a floresta em estágio inicial. Mas isso não foi suficiente para a realização das práticas de cultivo utilizadas pelos pequenos agricultores. $\mathrm{O}$ pousio, por exemplo, tornava-se inviável, uma vez que o corte raso ocorria sobre a floresta em estágio mais adiantado (MIGUEL; ZANONI, 1998).

Em 1994 foi elaborado o Plano de Gestão (PARANÁ, 1995), com a participação de 26 instituições, entre elas o IAP, no qual havia uma atenção maior às questões sociais, decorrentes principalmente dos impactos da restrição de uso dos recursos naturais, em relação ao Plano Integrado, este centrado na conservação (TEIXEIRA, 2004). Deste, manteve-se a classificação de agricultura empresarial e agricultura familiar e, para esta última, previu-se a produção controlada, com novas técnicas e destinada a nichos de mercados ou à realização de projetos de geração de renda que substituíssem as práticas incompatíveis com os objetivos da APA. Ainda, propunha convênios com instituições estaduais e federais para a regularização da questão fundiária e modificações na legislação. Observa-se aqui a presença das soluções anteriormente apresentadas pelos atores do órgão estadual.

A partir de convênio firmado com o IBAMA, a SPVS elaborou o Programa Guaraqueçaba, com projetos distintos que atuavam na pesquisa e na implantação de tecnologias para a conservação (SPVS, 1995). Tais projetos atendiam aos objetivos estabelecidos, como a realização das atividades previstas no Plano Operacional Anual (POA) do IBAMA dos anos de 1994, 1995 e 1996 (educação ambiental, diagnóstico cultural, desenvolvimento comunitário e conservação do estuário).

Esses documentos consideraram as exigências estabelecidas pelo IBAMA e por seus financiadores. São elas: gestão com a participação de outras instituições ambientais e de desenvolvimento estaduais, desenvolvimento de asso- 
ciações junto à população que se responsabilizassem pelo gerenciamento da sua produção, não mais para a defesa de seus interesses, além do respeito às práticas tradicionais de produção. Essas exigências não foram, necessariamente, articuladas nas propostas e ações de conservação e desenvolvimento local. Muitas vezes, em função do distanciamento dos novos atores dessas exigências, elas caminhavam paralelamente (TEIXEIRA, 2004).

O Macrozoneamento da APA foi revisto e publicado somente em 2001 (IPARDES, 2001). Herança do primeiro documento original, manteve a atenção especial à pequena agricultura, composta por produtores simples, menos tecnificados e de assalariados, em condições de subdesenvolvimento acentuado: "Esse contingente dificilmente conseguirá ter as restrições básicas resolvidas por ações voltadas à agricultura. Trata-se de um público-alvo de projetos específicos/especiais." (IPARDES, 2001, p. 49) Essa agricultura era considerada como atividade de subsistência e como atividade-suporte para outras ocupações. Por isso, deveria recorrer a outras atividades produtivas (geradoras de renda) como o artesanato e a agroindústria (IPARDES, 2001, p. 102). Nesse documento, faz-se referência a uma agricultura sustentável com “...pouco ou nenhum uso de agroquímicos, baixo nível de mobilização do solo, uso de sistemas de produção em que predominem cultivos com alto grau de cobertura do solo associados à agrossilvicultura" (IPARDES, 2001). As demais sugestões como financiamento, assistência técnica e abertura de vias de transporte permaneceram como propostas de desenvolvimento da agricultura local, em geral.

Enquanto os novos atores da conservação assumiam a gestão da APA de Guaraqueçaba, o IAP reduzia cada vez mais sua presença na região. O IBAMA desenvolve condições (recursos financeiros e cooperação técnica) para requerer sua responsabilidade sobre a gestão da APA de Guaraqueçaba. A partir de 1996, assume o controle das funções antes atribuídas ao IAP de fiscalização e licenciamento.

As relações amistosas e de cooperação com os demais agentes da proteção foram sendo gradativamente substituídas por relações de conflito de poder sobre o espaço protegido (TEIXEIRA, 2004). O IAP foi considerado pelos novos atores como permissivo diante da fiscalização e do licenciamento: por exemplo, ele licenciava para produtores sem título legal de propriedade. Ao mesmo tempo, as dificuldades financeiras e administrativas desse órgão afetaram sua capacidade de atuação na região. Em 1997, o
IAP fecha o seu escritório em Guaraqueçaba. Em 1999, o IBAMA questionou o IAP como instituição deliberativa em Guaraqueçaba, uma vez que a APA é federal. O IAP, então, cessa sua atuação na APA. Sua participação na gestão da APA passa a ser indireta, quando solicitado na elaboração dos planos e programas coordenados pelo IBAMA, não deixando de reafirmar a atenção especial à pequena agricultura local.

\section{Considerações finais}

As soluções para a pequena agricultura foram elaboradas pelos atores da conservação a partir de suas posições em um contexto que se modificou ao longo das duas décadas aqui consideradas. Esses atores sociais enfrentaram a situação da pequena agricultura e sua relação com a conservação, ao proporem e/ou realizarem as ações de conservação para as quais foram designados. Tal enfrentamento ocorreu a partir de suas formações profissionais, de suas relações com a conservação e com a pequena agricultura, de seus engajamentos com causas sociais ou ambientais, entre outros fatores.

As soluções encontradas pelos diferentes atores da conservação são consensuais no seguinte aspecto: elas foram propostas em função da conservação. No entanto, como alcançar esse objetivo a partir das condições de reprodução da pequena agricultura local?

Quando a resposta foi exigida dos primeiros atores da conservação nos anos 1980, estes apresentaram soluções a partir de sua formação profissional (engenheiros agrônomos e técnicos agrícolas), de suas funções em um órgão de terras, além do engajamento desses atores com questões sociopolíticas e ambientais. Diante da situação encontrada em Guaraqueçaba, o ponto de vista a partir do qual essa situação foi analisada resultou em uma perspectiva na qual, na relação entre os problemas da conservação e os problemas socioeconômicos da pequena agricultura, um não se sobrepunha ao outro. O sentido era: o que fazer em relação à pequena agricultura local, frente aos problemas fundiários, à falta de atenção dos programas de desenvolvimento agrícola, à falta de condições econômicas de reprodução da mesma e, também, da conservação?

Quando os novos atores da conservação entram em cena, engajados agora com o conservacionismo e as soluções técnico-científicas para a conservação, em discussão na década de 1990, a situação de conflito entre os neolatifundi- 
ários e a pequena agricultura já se encontrava amenizada. No entanto, a situação de conflito entre a regulamentação de uso dos recursos naturais e a pequena agricultura se agravou. Diante da disponibilidade de recursos para a conservação, diante da afinidade dos novos atores com a tendência do movimento ambiental e da organização das ONGs ambientalistas (cientifização e despolitização) e, ainda, diante de suas formações profissionais e de orientações dos financiadores da implantação da APA, novas soluções são propostas para a pequena agricultura. Ela deveria ser controlada através do desenvolvimento de técnicas de produção adequadas à "vocação" definida para Guaraqueçaba e/ou, ainda, através de programas de geração de renda, também adequados às restrições impostas pela conservação. Estudos e diagnósticos constatavam a inviabilidade da pequena agricultura diante das características econômicas, sociais e naturais de Guaraqueçaba. A viabilidade poderia estar garantida para aqueles agricultores que mantiveram condições, sobretudo econômicas, para o desenvolvimento de uma agricultura orgânica. Aos demais, restavam outras soluções, como o turismo e a produção artesanal.

O interesse principal não eram as condições sociais de produção que levavam o pequeno agricultor a realizar uma agricultura praticamente condenada, ainda que essas condições fossem apresentadas e reconhecidas. Interessavam suas práticas de uso dos recursos naturais, interessava o seu impacto sobre o meio natural. Nesse caso, o sentido era: o que fazer com a pequena agricultura local frente às exigências da inexorável conservação? Como controlar os impactos por ela causados?

Embora os novos atores também considerassem que o desenvolvimento da pequena agricultura era necessário, a matriz do olhar predominante não era o agricultor - a maior parte da população local, à mercê de grileiros e mergulhados na pobreza, sem escola e saúde - mas sim os impactos antrópicos causados por estes agricultores. A afinidade com a agricultura dos agrônomos e técnicos agrícolas do ITC/ ITCF engajados em movimentos por justiça social deu lugar à afinidade com o meio natural dos técnicos e pesquisadores das ciências biológicas e naturais, ou ainda das ciências sociais, engajados ou não no movimento ambiental.

No que se refere à transformação da situação encontrada pelos atores da conservação, a partir de suas matrizes, estudos indicam que, para a pequena agricultura, os resultados efetivos foram muito reduzidos, localizados, não alterando estruturalmente a condição socioeconômica da pequena agricultura local, indicando inclusive um empobrecimento da mesma em função das restrições impostas pela regulamentação de uso dos recursos naturais nos limites da APA (MIGUEL,1997; RODRIGUES, 2002). A aplicação da regulamentação, considerada inadequada por todos os atores da conservação, continuou sendo o principal regulador, o principal instrumento de controle da pequena agricultura em relação à conservação. As diferentes matrizes diante das condições objetivas de suas realizações (recursos financeiros, atenção das políticas públicas para a região, legislação ambiental, interesse dos grandes e médios proprietários, de ONGs ambientalistas, etc.) não foram capazes de provocar as mudanças desejadas pelos diferentes atores da conservação.

Nos anos seguintes ao período aqui analisado, outros fatores passaram a atuar sobre a situação local, tais como o desenvolvimento da agroecologia, realizado pela SEAB (TEIXEIRA, 2004) e a participação da população local na gestão da APA através de conselho gestor exigido pelo Sistema Nacional de Unidades de Conservação (SNUC) (TEIXEIRA; LIMONT, 2007), além da reestruturação recente do quadro técnico do IBAMA. Seguindo a trajetória deste artigo, a um novo contexto corresponde uma nova perspectiva em relação ao que se deve fazer com a pequena agricultura. Sem ser o resultado de um movimento intencional, sistematizado e estando influenciado por transformações no contexto nacional da conservação em unidades de conservação, há indícios de que pode estar havendo uma "síntese" das duas matrizes anteriores, "humanizando" a conservação. No entanto, é necessário investigação para verificar esta afirmação.

\section{Referências}

ACSELRAD, H. Políticas ambientais e construções democráticas. In: SILVA, M; DINIZ, N.; VIANA, G. (Org.) O desafio da sustentabilidade: um debate socioambiental no Brasil. São Paulo: Fundação Perseu Abramo, 2001.

BRITO, M. C. W. Unidades de conservação: intenções e resultados. São Paulo: Anablume/FAPESP, 2000.

DEAN, W. A ferro e a fogo: a história e a devastação da Mata Atlântica brasileira. São Paulo: Cia das Letras, 1996.

DIEGUES, A.C. Etnoconservação da natureza: enfoques alternativos. DIEGUES, A. C. (Org.). Etnoconservação: novos rumos para a proteção da natureza nos trópicos. São Paulo: Hucitec/NUAPAUB-USP, 2000. 
DOMINGUES, Z. H.; TEIXEIRA, C. Apontamentos gerais sobre a situação fundiária de Guaraqueçaba. Trabalho apresentado na disciplina Oficina II do Curso de Doutorado em Meio Ambiente e Desenvolvimento da UFPR. Curitiba, 2002.

FLEISHFRESSER, Vanessa. Nas redes de conservação: políticas públicas e construção social das microbacias hidrográficas. Curitiba, 1999. 225 p. Tese (Doutorado em Meio Ambiente e Desenvolvimento) - Universidade Federal do Paraná.

KARAM, K. F.; TOLEDO, V. Caracterização socioeconômica e cultural da população tradicional de Guaraqueçaba. Curitiba: IPARDES, 1996.

LEIS, H.; VIOLA, E. A emergência e evolução do ambientalismo no Brasil. Leis, H. O labirinto: ensaios sobre ambientalismo e globalização. São Paulo: Gaia; Blumenau: Fundação Universidade de Blumenau, 1996.

MACROZONEAMENTO da APA de Guaraqueçaba. Curitiba: IPARDES, 1990.

MIGUEL, L. de A . Formation, evolution et transformation d'un système agraire dans le sud du Brésil (Litoral Nord de l'état du Paraná): Une Paysannerie face à une politique de protection de l'environment: "Cronique d'une mort annoncée?" Paris, 1997. 293 p. Tese (Doutorado) - Institut National Agronomique Paris/Grignon.

MIGUEL, L. de A.; ZANONI, M. Práticas agroflorestais, políticas públicas e meio ambiente: o caso do litoral norte do Paraná. Extensão Rural, Santa Maria, DEAR/CPGEXR-CCRUFSM, ano 5, jan./dez. 1998.

PARANÁ - Secretaria de Estado do Meio Ambiente e Recursos Hídricos. Plano de Gestão Ambiental de Guaraqueçaba Área de Proteção Ambiental de Guaraqueçaba. Curitiba: IAP, 1995.

PARANÁ. Comitê Estadual de Meio Ambiente. Programa Estadual do Meio Ambiente. Curitiba, 1985.

PARANÁ. Secretaria Especial de Assuntos de Meio Ambiente e Recursos Hídricos. Programas para o Meio Ambiente. Curitiba, 1994.

PARANÁ. Secretaria do Planejamento. A gestão para o ecodesenvolvimento. Curitiba, 1987.

ROCHA, J. M. A sustentabilidade desfocada: as lógicas de políticas de desenvolvimento rural para áreas de proteção ambiental (APAs) - o caso de Guaraqueçaba, PR. Curitiba, 2004. Tese (Doutorado em Meio Ambiente e Desenvolvimento) - Universidade Federal do Paraná.
RODRIGUES, A. A sustentabilidade da agricultura em Guaraqueçaba: o caso da produção vegetal. Curitiba, 2002. 212 p. Tese (Doutorado em Meio Ambiente e Desenvolvimento) Universidade Federal do Paraná.

Sociedade de Pesquisa em Vida Selvagem e Educação Ambiental. (SPVS) Relatório anual 1994 do Programa Guaraqueçaba. Curitiba, mar. 1995.

Sociedade de Pesquisa em Vida Selvagem e Educação Ambiental. Relatório Anual 1993-1994 Programa Projeto viabilidade da agropecuária na região de Guaraqueçaba. Curitiba: SPVS, 1994.

SPVS/TNC - Sociedade de Pesquisa em Vida Selvagem e Educação Ambiental/TNC - The Nature Conservancy. Plano Integrado de conservação para a região de Guaraqueçaba. Relatório Anual. Curitiba, 1992.

TEIXEIRA, C. A proteção ambiental em Guaraqueçaba: uma construção social. Curitiba, 2004. 302 p. Tese (Doutoradoem Meio Ambiente e Desenvolvimento) - Universidade Federal do Paraná.

O desenvolvimento sustentável em unidade de conservação: a "naturalização" do social. Revista Brasileira de Ciência Sociais, São Paulo, ANPOCS, v. 20, n. 59, 2005.

TEIXEIRA, C; LIMONT, M. Os limites da participação da população local na gestão da APA de Guaraqueçaba: a institucionalização de uma possibilidade e as condições de seu aproveitamento. In: CONGRESSO BRASILEIRO DE SOCIOLOGIA, 13., Recife. 2007, Anais... Recife, 2007. Disponível em: $<$ http://www.sbs.org.br $>$ Acesso em: 10/10/2007.

URBAN, Teresa. Missão (quase) impossivel: aventuras e desventuras do movimento ambientalista no Brasil. São Paulo: Peirópolis, 2001.

ZANONI, M., RAYNAUT, C. Meio ambiente e desenvolvimento: imperativos para a pesquisa e a formação? Reflexões em torno do doutorado da UFPR. Cadernos de desenvolvimento e meio ambiente. Curitiba: Editora UFPR; Bordeaux: GRID, n. 1, 1994.

ZONEAMENTO da APA de Guaraqueçaba. Curitiba: IPARDES, 2001. 